\title{
Persistence to subcutaneous biological agents in Hungarian patients treated for inflammatory arthritis
}

This article was published in the following Dove Medical Press journal: Patient Preference and Adherence

\author{
Peter Takacs' \\ Urja Lathia ${ }^{2}$ \\ Janey Shin ${ }^{2}$ \\ Francois Nantel ${ }^{2}$ \\ 'Jan-Cil Hungary, Budapest, Hungary; \\ ${ }^{2}$ Medical Affairs, Janssen Inc., Toronto, \\ ON, Canada
}

\begin{abstract}
Background: The aim of the study was to compare drug survival rate of subcutaneous tumor necrosis factor alpha inhibitors in rheumatoid arthritis, ankylosing spondylitis, and psoriatic arthritis patients in Hungary.
\end{abstract}

Methods: This was a retrospective analysis using data collected from 5,647 patients over a period of 10 years who were treated with any of the following drugs: adalimumab (ADA), etanercept, certolizumab pegol (CZP), and golimumab (GLM). National Health Insurance Fund's hospital, drug reimbursement, and special reimbursement registry data have been used in this study. Drug survival rate was calculated according to Kaplan-Meier survival analysis. Propensity score matching was used to reduce the potential bias caused by the inhomogeneity resulting from demographic characteristics, patient pathways, or drug administration protocols. Both raw and propensity matched data were subject of pairwise comparison between the four subcutaneous therapies.

Results: The overall rate of persistence for the 4 biological therapies was between $53 \%$ and $61 \%$ after 1 year and between 14\% and 19\% after 4 years (follow-up time). Pairwise comparisons between therapies showed significant differences with GLM-treated patients showing longer median survival times than patients on other therapies. After propensity matching, these differences remained statistically significant between GLM and ADA or CZP over 4 years.

Conclusion: Hungarian show longer persistence to GLM compared to ADA and CZP.

Keywords: rheumatoid arthritis, ankylosing spondylitis, psoriatic arthritis, anti-TNF, persistence

\section{Introduction}

Immune-mediated rheumatic diseases (IMRDs), including rheumatoid arthritis (RA), psoriatic arthritis (PsA), and ankylosing spondylitis (AS), are chronic, immunemediated systemic diseases characterized by pain, inflammation, progressive joint damage, and a decline of physical function over time. Those diseases not only impact the quality of life negatively but also worsen life expectancy. Even though they are currently not curable, there are many therapeutic options available that can treat symptoms and slow progression of disease although they require long-term, often life-long treatment. Therefore, optimal drug management is fundamental to achieve the best possible outcome for these patients. An important breakthrough was the development of biological therapies including the self-injected anti-tumor necrosis factor agents subcutaneous tumor necrosis factor alpha inhibitors (SC-TNFis), adalimumab (ADA), etanercept (ETA), golimumab (GLM), and certolizumab pegol (CZP). ${ }^{1-3}$

Drug persistence is a comprehensive measure of therapeutic success and depends on a variety of factors including efficacy, safety, tolerability, and patient satisfaction. Indeed, suboptimal adherence and persistence are common and complex problems among patients 
with chronic diseases and have a negative impact on outcomes. ${ }^{4,5}$ In a US retrospective cohort study, only $37 \%$ of patients were adherent and $83 \%$ were persistent in the first year of therapy. The lowest adherence (17\%) and persistence (70\%) were observed among young adult patients by year $3 .{ }^{6}$ In another retrospective analysis of Swedish patients, median survival of persistence was 15.8, 15.1, 15.3, and 18.1 months for ADA, ETA, CZP, and GLM, respectively. ${ }^{7}$ Therefore, the persistence can be different between biological agents, ${ }^{7-9}$ between countries ${ }^{10}$ and be lower than that found in clinical trial extension studies. ${ }^{4}$

The objective of this study was to compare the persistence to therapy of all inflammatory arthritis patients treated with any of the SC-TNFi agent available in Hungary from 2010 to 2016 in a real-world setting.

\section{Methods}

\section{Patient enrollment}

The data source for this retrospective analysis was the database of the Hungarian National Health Insurance Fund (NHIF). The analysis was done based on the ethical approval of Central Scientific Ethical Committee no OGYI/58486/2016/ EKU. The analysis was performed with the help of an independent data research company, Healthware Ltd., Budapest, Hungary. NHIF has a right to handle patients data based on law (Act No 80/1997 on mandatory health insurance coverage) and has a right to share it on a claim basis (based on Act 63/2012 on the reuse of public data).

Only NHIF had direct access to patient-level data, other members of the research group had only access to those data indirectly, through NHIF. Thus, individual patients' consent was not necessary for this study.

The study design is shown in Figure 1. Included were all SC-TNFi naive inflammatory arthritis patients, who started at least one biological therapy and who dispensed their first SC-TNFi drug for RA, AS, or PsA from May 1, 2010 to December 31, 2016. This first dispensation is referred to as the "index date". "Naïve" means no previous dispensation of a biological agent between January 1, 2005 and May 1, 2010 (washout period). Exclusion criteria were as follows: patients below 18 years at the time of the index date, patients who were indexed after to January 1, 2016 (ensuring minimum 12 months of follow-up) and patients who initiated SC-TNFi treatment for a disease other than IMRD, based on the relevant codes according to WHO International Statistical Classification of Diseases 10th Revision (ICD-10) at the index date or the nearest ICD code to the index date. The ICD codes used were: M05.8, M05.9, M06.0, and M06.9 for RA; M08.1, M45, and M46 for ankylopoetic spondylitis; and L45 and M07.0-M07.3 for PsA.

Treatment discontinuation was defined by the occurrence of any of the following events: termination (no more prescription) or reinduction of the biological therapy (at least a 180-day pause of biological therapy until the next prescription) or switching to a different biological therapy. Sensitivity analysis was carried out to identify the most appropriate gap length for treatment discontinuation. After a 180-day gap in the biological treatment, there were only a very limited number of patients who continued the same treatment with no other biological treatment in between. These cases were considered as reinduction of biological therapy. Data were censored for patients where death of any cause occurred over the study period.

\section{Statistical analysis}

All statistical tests were performed using R software. Persistence estimates were derived using nonparametric survival analysis. Kaplan-Meier survival functions were estimated with treatment discontinuation as failure event. Patients were right-censored for death or end of the study period. Persistence analysis were also carried out on propensity score-matched (PSM) cohorts, attempting to adjust for potential selection bias. The following three PSM cohorts

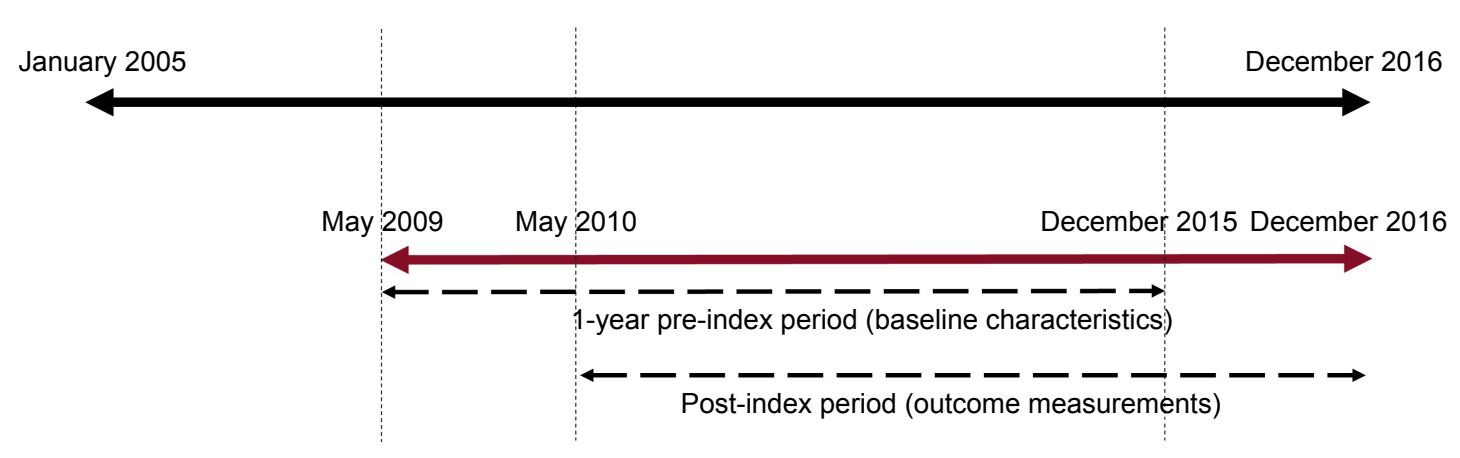

Figure I Study design. 
Table I Summary of baseline characteristics for the included patients overall and stratified by index therapy

\begin{tabular}{|c|c|c|c|c|c|}
\hline & ADA $(n=2,085)$ & ETA $(n=1,339)$ & $\operatorname{CZP}(n=I, 05 I)$ & $\operatorname{GLM}^{a}(n=I, 172)$ & Total $(n=5,647)$ \\
\hline Age - mean (SD) & 48.57 (13.19) & $50.09(14.17)$ & $54.87(12.47)$ & 48.97 (13.39) & $49.67(13.66)$ \\
\hline Female - n (\%) & $\mathrm{I}, 20 \mathrm{I}(57.6)$ & $899(67.1)$ & $895(85.2)$ & $663(56.6)$ & $3,658(64.8)$ \\
\hline \multicolumn{6}{|l|}{ IMRD - n (\%) } \\
\hline Psoriatic arthritis & $350(16.8)$ & $193(14.4)$ & NA & $189(16.1)$ & $733(13.0)$ \\
\hline Ankylosing spondylitis & $914(43.8)$ & $435(32.5)$ & $27(2.6)$ & $469(40.0)$ & $\mathrm{I}, 845(32.7)$ \\
\hline Rheumatoid arthritis & $821(39.4)$ & $711(53.1)$ & $\mathrm{I}, 024(97.3)$ & $515(43.9)$ & $3,070(54.4)$ \\
\hline Charlton Comorbidity Index - mean (SD) & $0.45(0.83)$ & $0.5 I(0.9)$ & $0.43(0.75)$ & $0.4 I(0.73)$ & $0.45(0.8 \mathrm{I})$ \\
\hline \multicolumn{6}{|l|}{ Co-medication - n (\%) } \\
\hline NSAIDs & $\mathrm{I}, 527(73.2)$ & $918(68.6)$ & $66 \mid(62.9)$ & $825(70.4)$ & 3,93I (7I.9) \\
\hline DMARDs & $\mathrm{I}, 095(52.5)$ & $758(56.6)$ & $842(80.1)$ & $576(49.1)$ & 3,27I (59.8) \\
\hline Hospitalized - n (\%) & $76 \mid(36.5)$ & $540(40.3)$ & $453(43.1)$ & 418 (35.7) & $2,172(39.7)$ \\
\hline
\end{tabular}

Note: ${ }^{\text {TThe }}$ was one patient with two different IMRD codes at the index date.

Abbreviation: IMRD, immune-mediated rheumatic disease.

were created: GLM vs ADA, GLM vs ETA, and GLM vs CZP. Variables included in the propensity score were indication, index year, gender, age, comorbidities, concomitant drug use (NSAIDs and DMARDs), and hospitalization.

The propensity score was derived from a logit model as the predicted probability of initiating SC-TNFi treatment with GLM given the baseline characteristics presented in Table 1. Pairs were matched based on a greedy algorithm using 5 to 1 digit matching. Balance across strata was evaluated in covariates pre- and post-matching by Pearson's chi-squared test and Student's $t$-test. Sensitivity analysis of the adjusted persistence was performed by analyzing only the 1 year, 2 years, and 3 years persistence. In each case, patients with longer persistence were censored at the given time point.

\section{Results}

A total of 5,647 patients were identified of which 2,085, 1,339, 1,051, and 1,172 were treated with ADA, ETA, CZP, and GLM, respectively. The mean age of the included patients was 49.67 years and most patients were female $(64.8 \%)$ (Table 1). A larger proportion of patients treated with ETA and CZP were for RA (97.3\% and 53.1\%, respectively) compared to patients treated with ADA or GLM (39.4\% and $43.9 \%$, respectively). Consequently, the use of concomitant DMARDs was more common in ETA- and CZP-treated patients (56.6\% and $80.1 \%$, respectively) compared to ADAand GLM-treated patients ( $52.5 \%$ and $49.1 \%$, respectively).

Unadjusted persistency to SC-TNFi is shown in Figure 2A. After 1 year of therapy, the percentages of persistent patients were $56 \%, 54 \%, 53 \%$, and $61 \%$ for ADA, ETA, CZP, and GLM, respectively. The higher persistency of GLM vs ADA, ETA, or CZP was consistent over 4 years $(P<0.001)$. Indeed, the median (95\% CI) survival time was 457 (427-490), 415 (382-454), 402 (368-438), and 541 (496-618) days for ADA, ETA, CZP, and GLM, respectively.

Since the groups were unevenly matched (Table 2), propensity score matching was carried out to limit any potential biases. Baseline characteristics of matched cohort are shown in Table 3 and show no statistically significant differences between each of the two matched arms. The persistence of matched GLM-treated patients compared to patients treated with ADA, ETA, and CZP is shown in Figure 2B-D, respectively. Although the propensity score matching recessed the effect size of GLM vs the other SC-TNFi, patients treated with GLM still showed a significantly longer persistence than ADA- $(P=0.009)$ and CZP-treated patients $(P=0.041)$. Conversely, GLM- and ETA-treated patient showed similar persistence $(P=0.209)$.

A sensitivity analysis was carried out by comparing the persistence of patients treated with GLM to other SC-TNFi over individual index dates and with follow-ups of 1, 2, or 3 years. Interestingly, GLM-treated patients with an index year of 2010 or 2011 had significantly better persistence than ADA-treated patients and ETA-treated patients at all follow-up periods $(P<0.05)$. GLM-treated patients with an index year of 2010 had significantly better persistence than CZP-treated patients at a 1 -year follow-up period $(P=0.05)$; however, no statistical difference was seen at 2 and 3 years of follow-up. Conversely, GLM-treated patients with an index year of 2011 had significantly better persistence than CZP-treated patients at 2 and 3 years of follow-up $(P<0.05)$. In contrast, the GLM-treated patient cohort from 2012 onward did not systematically show longer persistence compared to the other groups (data not shown). 

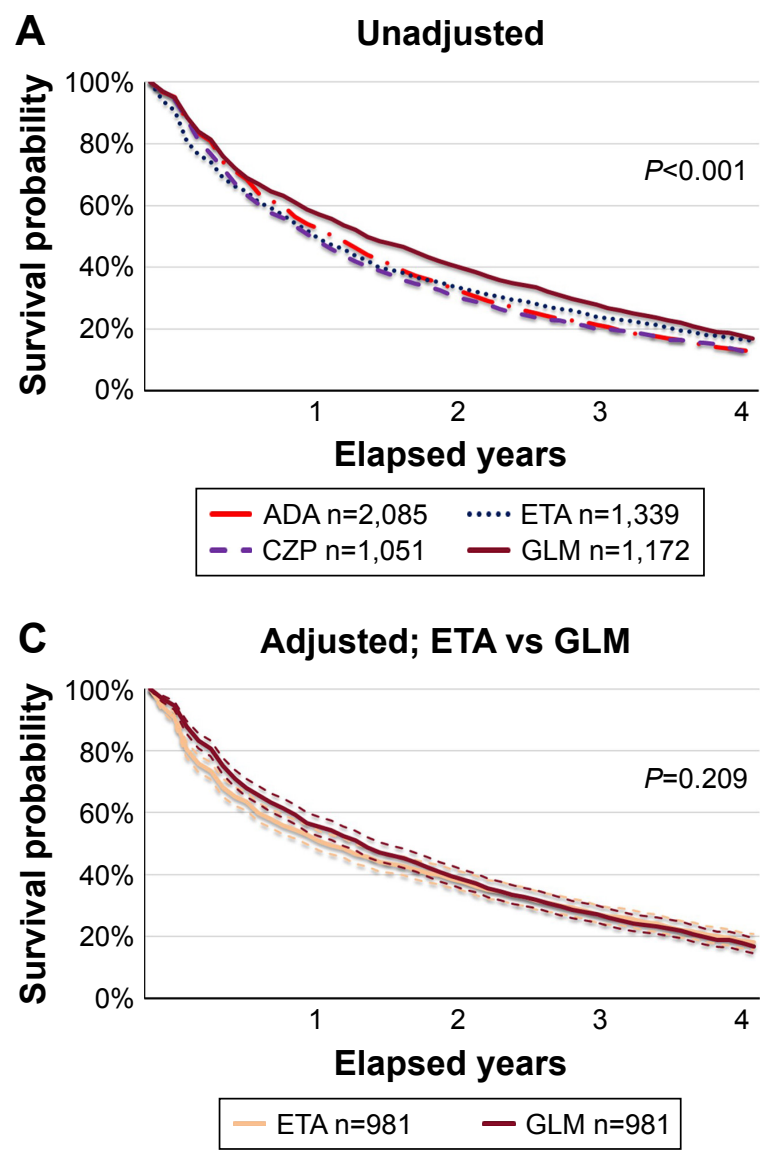

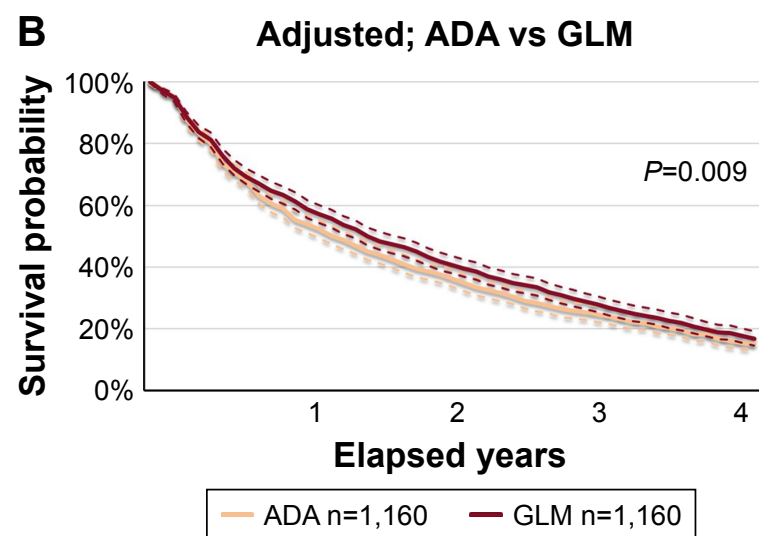

D Adjusted; CZP vs GLM

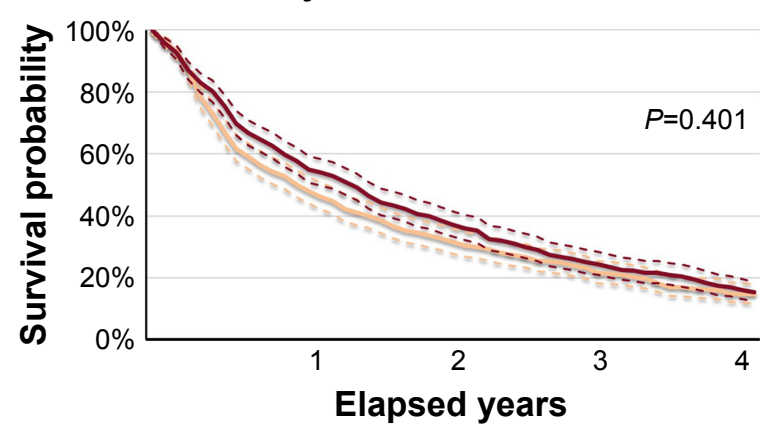

Elapsed years

Figure 2 Unadjusted (A) and adjusted (B-D) persistence to SC-TNFi therapy.

Abbreviations: ADA, adalimumab; CZP, certolizumab pegol; ETA, etanercept; GLM, Golimumab; SC-TNFi, subcutaneous tumor necrosis factor alpha inhibitors.

Table 2 Pre-matching baseline characteristics

\begin{tabular}{|c|c|c|c|c|c|c|c|c|c|}
\hline & \multicolumn{3}{|c|}{ ADA vs GLM } & \multicolumn{3}{|c|}{ ETA vs GLM } & \multicolumn{3}{|c|}{ CZP vs GLM } \\
\hline & ADA & GLM & $P$-value & ETA & GLM & $P$-value & CZP & GLM & $P$-value \\
\hline$n$ & 2,085 & 1,172 & & 1,339 & $\mathrm{I}, 172$ & & $|, 05|$ & $\mathrm{I}, 172$ & \\
\hline IMRD - n (\%) & & & 0.037 & & & $<0.001$ & & & $<0.001$ \\
\hline Ankylosing spondylitis & $914(43.8)$ & $469(40.0)$ & & $435(32.5)$ & $469(40.0)$ & & $27(2.6)$ & $469(40.0)$ & \\
\hline Psoriatic arthritis & $350(16.8)$ & $189(16.1)$ & & $193(14.4)$ & $189(16.1)$ & & NA & $189(16.1)$ & \\
\hline Rheumatoid arthritis & $821(39.4)$ & $515(43.9)$ & & $711(53.1)$ & $515(43.9)$ & & I,023 (97.3) & $515(43.9)$ & \\
\hline Index year - n (\%) & & & $<0.001$ & & & $<0.001$ & & & $<0.001$ \\
\hline 2010 & $204(9.8)$ & $216(18.4)$ & & $187(14.0)$ & $216(18.4)$ & & $113(10.8)$ & $216(18.4)$ & \\
\hline 2011 & $371(17.8)$ & $313(26.7)$ & & $312(23.3)$ & $314(26.8)$ & & $211(20.1)$ & $314(26.8)$ & \\
\hline 2012 & $354(17.0)$ & $160(13.7)$ & & $199(14.9)$ & $160(13.6)$ & & $224(21.3)$ & $160(13.6)$ & \\
\hline 2013 & $369(17.7)$ & $258(22.0)$ & & $194(14.5)$ & $258(22.0)$ & & $150(14.3)$ & $258(22.0)$ & \\
\hline 2014 & $412(19.8)$ & $209(17.8)$ & & $178(13.3)$ & $209(17.8)$ & & $175(16.7)$ & $209(17.8)$ & \\
\hline 2015 & $375(18.0)$ & $16(1.4)$ & & $269(20.1)$ & $16(1.4)$ & & $178(16.9)$ & $16(1.4)$ & \\
\hline Female - n (\%) & $\mathrm{I}, 20 \mathrm{I}(57.6)$ & $663(56.6)$ & 0.607 & $899(67.1)$ & $664(56.6)$ & $<0.001$ & $895(85.2)$ & $664(56.6)$ & $<0.001$ \\
\hline Age group, years - n (\%) & & & $0.44 I$ & & & 0.003 & & & $<0.001$ \\
\hline $00-19$ & $16(0.8)$ & NA & & $22(1.6)$ & NA & & NA & NA & \\
\hline 20-29 & $167(8.0)$ & $75(6.4)$ & & $94(7.0)$ & $75(6.4)$ & & $33(3.1)$ & $75(6.4)$ & \\
\hline $30-39$ & $348(16.7)$ & $214(18.2)$ & & $213(15.9)$ & $214(18.2)$ & & $82(7.8)$ & $214(18.2)$ & \\
\hline
\end{tabular}


Table 2 (Continued)

\begin{tabular}{|c|c|c|c|c|c|c|c|c|c|}
\hline & \multicolumn{3}{|c|}{ ADA vs GLM } & \multicolumn{3}{|c|}{ ETA vs GLM } & \multicolumn{3}{|c|}{ CZP vs GLM } \\
\hline & ADA & GLM & $P$-value & ETA & GLM & $P$-value & CZP & GLM & $P$-value \\
\hline $40-49$ & $463(22.2)$ & $253(21.6)$ & & 237 (I7.7) & $253(21.6)$ & & $183(17.4)$ & $253(21.6)$ & \\
\hline $50-59$ & $637(30.6)$ & $363(30.9)$ & & $4 \mid 8(3 \mid .2)$ & $363(30.9)$ & & $360(34.3)$ & 363 (30.9) & \\
\hline $60-69$ & $362(17.4)$ & $200(17.1)$ & & $258(19.3)$ & $200(17.1)$ & & $282(26.8)$ & $200(17.1)$ & \\
\hline $70+$ & $92(4.4)$ & $62(5.3)$ & & $97(7.2)$ & $62(5.3)$ & & $107(10.2)$ & $62(5.3)$ & \\
\hline $\mathrm{CCl}$ - mean (SD) & $0.45(0.83)$ & $0.41(0.73)$ & 0.224 & $0.5 \mathrm{I}(0.90)$ & $0.41(0.73)$ & 0.003 & $0.43(0.75)$ & $0.4 I(0.73)$ & 0.647 \\
\hline NSAIDs & I,527 (73.2) & $825(70.4)$ & 0.092 & $918(68.6)$ & $826(70.4)$ & 0.334 & $66 \mid(62.9)$ & $826(70.4)$ & $<0.001$ \\
\hline DMARDs & $1,095(52.5)$ & $576(49.1)$ & 0.074 & $758(56.6)$ & $577(49.2)$ & $<0.001$ & $842(80.1)$ & $577(49.2)$ & $<0.001$ \\
\hline Hospitalized - n (\%) & $76 I$ (36.5) & $418(35.7)$ & 0.65 & $540(40.3)$ & $418(35.6)$ & 0.018 & $453(43.1)$ & $418(35.6)$ & $<0.001$ \\
\hline
\end{tabular}

\section{Discussion}

As local factors, including reimbursement system, prescribing behaviors, restrictions, and others may deeply impact drug using habits, we can learn a lot from cross-country comparisons of similar outcomes. Therefore, we followed the logic and research plan of Dalén et $\mathrm{al}^{7}$ in a different country,
Hungary in this case, where all four SC-TNFis were indicated, available and used by IMRD patients. The data were collected from the NHIF which includes the totality of the population of Hungary. Therefore, the results are highly generalizable. Overall, the retention in Hungarian arthritis patients was between $30 \%$ and $40 \%$ at 2 years, slightly

Table 3 Post-matching baseline characteristics

\begin{tabular}{|c|c|c|c|c|c|c|c|c|c|}
\hline & \multicolumn{3}{|c|}{ ADA vs GLM } & \multicolumn{3}{|c|}{ ETA vs GLM } & \multicolumn{3}{|c|}{ CZP vs GLM } \\
\hline & ADA & GLM & $P$-value & ETA & GLM & $P$-value & CZP & GLM & $P$-value \\
\hline$n$ & 1,160 & 1,160 & & 981 & 981 & & 525 & 525 & \\
\hline IMRD - n (\%) & & & 0.93 & & & 0.978 & & & 0.599 \\
\hline Ankylosing spondylitis & $470(40.5)$ & $461(39.7)$ & & $338(34.5)$ & $34 I(34.8)$ & & $20(3.8)$ & $21(4.0)$ & \\
\hline Psoriatic arthritis & $185(15.9)$ & $187(16.1)$ & & $142(14.5)$ & $139(14.2)$ & & $504(96.0)$ & $504(96.0)$ & \\
\hline Rheumatoid arthritis & $505(43.5)$ & $512(44.1)$ & & $50 \mathrm{I}(5 \mathrm{I} . \mathrm{I})$ & $50 \mathrm{I}(5 \mathrm{I} . \mathrm{I})$ & & NA & NA & \\
\hline Index year - n (\%) & & & 0.857 & & & 1 & & & 0.807 \\
\hline 2010 & $192(16.6)$ & $210(18.1)$ & & $178(18.1)$ & I78 (I8.I) & & $106(20.2)$ & $116(22.1)$ & \\
\hline 2011 & $324(27.9)$ & $308(26.6)$ & & $283(28.8)$ & $279(28.4)$ & & 157 (29.9) & $158(30.1)$ & \\
\hline 2012 & $149(12.8)$ & $160(13.8)$ & & $152(15.5)$ & $152(15.5)$ & & $57(10.9)$ & $60(11.4)$ & \\
\hline 2013 & $258(22.2)$ & $257(22.2)$ & & $182(18.6)$ & $186(19.0)$ & & $112(21.3)$ & $94(17.9)$ & \\
\hline 2014 & $221(19.1)$ & $209(18.0)$ & & $170(17.3)$ & $170(17.3)$ & & $80(15.2)$ & $85(16.2)$ & \\
\hline 2015 & $16(1.4)$ & $16(1.4)$ & & $16(1.6)$ & $16(1.6)$ & & $13(2.5)$ & $12(2.3)$ & \\
\hline Female - n (\%) & $678(58.4)$ & $661(57.0)$ & 0.501 & $633(64.5)$ & $623(63.5)$ & 0.672 & $437(83.2)$ & $425(81.0)$ & 0.376 \\
\hline Age group, years - n (\%) & & & 0.931 & & & 0.988 & & & 0.923 \\
\hline $00-19$ & $72(6.2)$ & $72(6.2)$ & & NA & NA & & $10(1.9)$ & I5 (2.9) & \\
\hline $20-29$ & $209(18.0)$ & $213(18.4)$ & & $64(6.5)$ & $59(6.0)$ & & $46(8.8)$ & $47(9.0)$ & \\
\hline $30-39$ & $263(22.7)$ & $248(21.4)$ & & $159(16.2)$ & $165(16.8)$ & & $90(17.1)$ & $90(17.1)$ & \\
\hline $40-49$ & $357(30.8)$ & $363(31.3)$ & & $182(18.6)$ & $186(19.0)$ & & $207(39.4)$ & 204 (38.9) & \\
\hline $50-59$ & $200(17.2)$ & $196(16.9)$ & & $332(33.8)$ & $324(33.0)$ & & $126(24.0)$ & $117(22.3)$ & \\
\hline $60-69$ & $56(4.8)$ & $62(5.3)$ & & $183(18.7)$ & I8I (I8.5) & & $45(8.6)$ & $50(9.5)$ & \\
\hline $70+$ & NA & NA & & $57(5.8)$ & $60(6.1)$ & & NA & NA & \\
\hline $\mathrm{CCl}$ - mean (SD) & $0.38(0.72)$ & $0.4 I(0.72)$ & 0.358 & $0.45(0.80)$ & $0.45(0.76)$ & 0.908 & $0.44(0.72)$ & $0.45(0.76)$ & 0.867 \\
\hline NSAIDs & $834(71.9)$ & $821(70.8)$ & 0.582 & $683(69.6)$ & $680(69.3)$ & 0.922 & $335(63.8)$ & $340(64.8)$ & 0.797 \\
\hline DMARDs & $569(49.1)$ & $575(49.6)$ & 0.836 & $544(55.5)$ & $533(54.3)$ & 0.65 & $402(76.6)$ & $398(75.8)$ & 0.828 \\
\hline Hospitalized - n (\%) & $396(34.1)$ & $412(35.5)$ & 0.513 & $398(40.6)$ & $391(39.9)$ & 0.782 & $204(38.9)$ & $205(39.0)$ & I \\
\hline
\end{tabular}


lower than in Sweden patients $(40 \%-50 \%){ }^{7}$ in a German prospective cohort (45.5\%), ${ }^{11}$ and much lower in Spanish $(73.3 \%)^{12}$ or Japanese patients $(40 \%-70 \%$ depending on the agent). ${ }^{8}$ The results presented here shows that Hungarian IMRD patients treated with GLM had longer persistency than patients treated with ADA, ETA, or CZP. This was also observed in the Swedish and Japanese cohorts. ${ }^{7,8}$ However, it is obvious from the baseline characteristics that these drugs were used in different patient types and many factors could explain this effect, some of which could be from selection biases inherent to these kinds of analyses. Indeed, gender, age, comorbidities, indication, and the index year have all been shown to impact adherence and/or retention. ${ }^{6,13-15}$

Therefore, propensity score matching was used to limit those biases and it was found to recess the effect size between GLM and the other SC-TNFis. Nonetheless, a significant difference was still observed between GLM- and ADAand between GLM- and CZP-treated patients. A longer persistency of GLM-treated patient was observed in other studies. ${ }^{7,16}$ One possible factor to explain this difference is treatment adherence as two previous studies in the United States and Canada have shown that there was a higher proportion of patients who were adherent to therapy when treated with GLM compared to other SC-TNFis. ${ }^{6,17}$ The better adherence found in GLM-treated patients could be the result of a simpler, less frequent dosing regimen (monthly vs once every 1-2 weeks).

Other, unmeasured variables could explain this effect in the matched cohorts as the sensitivity analysis showed that the better persistence of GLM over ADA or CZP was more predominant in patients that initiated treatment in 2010-2011. One possibility is a difference between disease activity among patients over the treatment period as previous studies have shown that IMRD patients have been diagnosed and treated with a biological agent earlier over the past decades with a higher likelihood of having a lower disease burden and chances for a better outcome. ${ }^{18,19}$

There are a number of limitations to this study. First, the data were extracted from an administrative database which is reliant on the quality of the coding and did not contain clinical outcome measures such as disease activity; therefore, reasons for discontinuation of therapy could not be assessed. Also, this study was confined to patients identified within the time frame where all four SC-TNFis were available, affecting the overall sample size. An analysis of the individual indications was not performed due to concerns in the design stage that such a study would be under-powered. Infliximab was not included in the cohort due to the IV nature of delivery, which impacts persistency and adds bias. One strength of the study is that Hungary has one national payer, covering all patients, and the drug is provided in an outpatient setting, administered in the hospital with minimal out of pocket co-payments for patients. Therefore, capture is comprehensive. This limits external biases given that this is a homogenous system.

\section{Acknowledgments}

Special thanks to Pal Geher, MD, PhD, for his help in the ethical submission and to Healthware Ltd, an independent data research company whose employees performed the technical work on the database. Their work was funded and managed by Janssen, with additional thanks to Miklos Bacskai, MD, Tamas Balazs, PhD, and Christophe Chort. The research leading to these results has received funding from Janssen Canada. Sponsor employees had participated in the study design, data interpretation, and writing of the method part in the manuscript. The sponsor of the study did not participate in the data collection and data analysis. Employees of an independent consulting company (Healthware Consulting Ltd.) received funding for contribution to the study design and data analyses.

\section{Disclosure}

All authors are employees of Janssen Inc. The authors report no other conflicts of interest in this work.

\section{References}

1. Coates LC, Gossec L, Ramiro S, et al. New GRAPPA and EULAR recommendations for the management of psoriatic arthritis. Rheumatology. 2017;56(8):1251-1253.

2. Smolen JS, Landewé R, Breedveld FC, et al. EULAR recommendations for the management of rheumatoid arthritis with synthetic and biological disease-modifying antirheumatic drugs: 2013 update. Ann Rheum Dis. 2014;73(3):492-509.

3. Smolen JS, Schöls M, Braun J, et al. Treating axial spondyloarthritis and peripheral spondyloarthritis, especially psoriatic arthritis, to target: 2017 update of recommendations by an international task force. Ann Rheum Dis. 2018;77(1):3-17.

4. Ziegelbauer K, Kostev K, Hübinger M, et al. The impact of non-persistence on the direct and indirect costs in patients treated with subcutaneous tumour necrosis factor-alpha inhibitors in Germany. Rheumatology. 2018; 57(7):1276-1281.

5. Contreras-Yáñez I, Cabiedes J, Villa AR, Rull-Gabayet M, PascualRamos V. Persistence on therapy is a major determinant of patient-, physician- and laboratory-reported outcomes in recent-onset rheumatoid arthritis patients. Clin Exp Rheumatol. 2010;28(5):748-751.

6. Calip GS, Adimadhyam S, Xing S, Rincon JC, Lee WJ, Anguiano RH. Medication adherence and persistence over time with self-administered TNF-alpha inhibitors among young adult, middle-aged, and older patients with rheumatologic conditions. Semin Arthritis Rheum. 2017;47(2): $157-164$

7. Dalén J, Svedbom A, Black CM, et al. Treatment persistence among patients with immune-mediated rheumatic disease newly treated with subcutaneous TNF-alpha inhibitors and costs associated with nonpersistence. Rheumatol Int. 2016;36(7):987-995. 
8. Ebina K, Hashimoto M, Yamamoto W, et al. Drug retention and discontinuation reasons between seven biologics in patients with rheumatoid arthritis - The ANSWER cohort study. PLoS One. 2018;13(3):e0194130.

9. Roberts L, Tymms K, de Jager J, et al. The CEDAR Study: A Longitudinal Study of the Clinical Effects of Conventional DMARDs and Biologic DMARDs in Australian Rheumatology Practice. Int $J$ Rheumatol. 2017;2017:1-8.

10. Finckh A, Neto D, Iannone F, et al. The impact of patient heterogeneity and socioeconomic factors on abatacept retention in rheumatoid arthritis across nine European countries. RMD Open. 2015;1(1):e00040.

11. Krüger K, Burmester GR, Wassenberg S, Bohl-Bühler M, Thomas MH. Effectiveness and safety of golimumab in patients with rheumatoid arthritis, psoriatic arthritis and ankylosing spondylitis under real-life clinical conditions: non-interventional GO-NICE study in Germany. BMJ Open. 2018;8(6):e021082.

12. Hernandez MV, Sanchez-Piedra C, Garcia-Magallon B, et al. Factors associated with long-term retention of treatment with golimumab in a real-world setting: an analysis of the Spanish BIOBADASER registry. Rheumatol Int. 2018;55(3):1-7.

13. van den Reek J, Kievit W, Gniadecki R, et al. Drug survival studies in dermatology:principles, purposes, and pitfalls. J Invest Dermatol. 2015; 135(7):1-5.

14. Iannone F, Gremese E, Atzeni F, et al. Longterm retention of tumor necrosis factor- $\alpha$ inhibitor therapy in a large italian cohort of patients with rheumatoid arthritis from the GISEA registry: an appraisal of predictors. J Rheumatol. 2012;39(6):1179-1184.
15. Lathia U, Ewara EM, Nantel F. Impact of adherence to biological agents on health care resource utilization for patients over the age of 65 years with rheumatoid arthritis. Patient Prefer Adherence. 2017;11: 1133-1142.

16. Svedbom A, Storck C, Kachroo S, Govoni M, Khalifa A. Persistence with golimumab in immune-mediated rheumatic diseases: a systematic review of real-world evidence in rheumatoid arthritis, axial spondyloarthritis, and psoriatic arthritis. Patient Prefer Adherence. 2017;11: 719-729.

17. Bhoi P, Bessette L, Bell MJ, Tkaczyk C, Nantel F, Maslova K. Adherence and dosing interval of subcutaneous antitumour necrosis factor biologics among patients with inflammatory arthritis: analysis from a Canadian administrative database. BMJ Open. 2017;7(9):e015872.

18. Sørensen J, Hetland ML. All departments of rheumatology in Denmark. Diagnostic delay in patients with rheumatoid arthritis, psoriatic arthritis and ankylosing spondylitis: results from the Danish nationwide DANBIO registry. Ann Rheum Dis. 2015;74(3):e12.

19. Thorne C, Bensen WG, Choquette D, et al. Effectiveness and safety of infliximab in rheumatoid arthritis: analysis from a Canadian multicenter prospective observational registry. Arthritis Care Res. 2014;66(8): $1142-1151$.
Patient Preference and Adherence

\section{Publish your work in this journal}

Patient Preference and Adherence is an international, peer-reviewed, open access journal that focuses on the growing importance of patient preference and adherence throughout the therapeutic continuum. Patient satisfaction, acceptability, quality of life, compliance, persistence and their role in developing new therapeutic modalities and compounds to optimize

\section{Dovepress}

clinical outcomes for existing disease states are major areas of interest for the journal. This journal has been accepted for indexing on PubMed Central. The manuscript management system is completely online and includes a very quick and fair peer-review system, which is all easy to use. Visit http://www. dovepress.com/testimonials.php to read real quotes from published authors. 